\title{
Better to Stay or Go? A Longitudinal Study of Mobility over the Compulsory Educational Life Course
}

\author{
Amy Sweet $^{1}$ (D) Richard Harris ${ }^{1} \cdot$ David Manley $^{1}$
}

Received: 23 November 2017 / Accepted: 26 June 2018 /

Published online: 1 August 2018

(C) The Author(s) 2018

\begin{abstract}
There has been substantial discussion in the literature about where you grow up and if whether or not you experience social and spatial mobility during childhood has substantial bearing upon later life achievement (Pribesh and Downey Demography, 36, 21-534, 1999; Gasper et al. Social Science Research, 39(3), 459-476, 2010; Sharkey and Elwert American Journal of Sociology, 116(6), 1934-1981, 2011). This paper utilises data from the National Pupil Database (NPD) and a quantitative framework to explore the impact of residential mobility on educational outcomes. Many previous studies of neighbourhood mobility have used point in time measures when studying inequality, which means that an individual's neighbourhood trajectory is overlooked. We follow a single cohort of pupils over an eleven year time period to analyse their mobility along with their individual characteristics to provide a clear understanding of who is moving and the association this has on them in terms of educational attainment. We also use the index of multiple deprivation (IMD) as a measure of neighbourhood deprivation to determine to what extent there is a trade up in terms of neighbourhood over the educational life course. Our findings show that moving home has a negative impact on educational attainment compared to those that stay in the same location throughout the educational life cycle. Those that 'trade up' in terms of quality of neighbourhood still do not achieve the same educational outcomes as their peers who live in a lower deprived neighbourhood throughout their schooling.
\end{abstract}

Keywords Residential mobility · Neighbourhood - Deprivation · Educational attainment

Amy Sweet

amy.sweet@bristol.ac.uk

Richard Harris

rich.harris@bristol.ac.uk

David Manley

d.manley@bristol.ac.uk

1 School of Geographical Sciences, University of Bristol, University Road, Bristol BS8 1SS, UK 


\section{Introduction}

Where people live and where they move over their life time are important factors for understanding a wide range of outcomes in later life. There is a strongly held belief to suggest that the circumstances a child is born into shapes their life course (SMCP 2015). The key concern is that those born poor are likely to remain poor as they transition into adulthood (SMCP 2015; van Ham et al. 2014). Research also suggests that the duration, depth and the age of exposure to poverty are decisive (Hedman et al. 2013). The younger children are, the longer they live in poverty and the more extreme the poverty is, the more severe the effects are in adulthood (Brooks-Gunn and Duncan 1997). Van Ham et al. (2014) highlight evidence of the negative neighbourhood effects of living in deprived neighbourhoods on a diverse range of outcomes, including educational achievement, moves in to and out of work, and social mobility.

During the last decade, partially due to the recent global economic crisis, the debate around social mobility and equality of opportunity has been reignited. The Social Mobility and Child Poverty Commission was set up in 2012 to monitor the progress of government and others in improving social mobility and reducing child poverty in the UK. Traditionally, within academic and political spheres, mobility largely has been discussed in terms of socio-economic outcomes, with a lack of focus on the spatial element of mobility. This paper does not, therefore, merely highlight if a move takes place but also where pupils have moved from and to bringing more of a focus on geography.

Sharkey (2012) argues that it is essential to know what type of resources, risks and role models are present in a child's neighbourhood at various points in her or his development. It is during childhood and adolescence that individuals are more susceptible to the consequences of a social and environmental change (Morris et al. 2016), yet there is a lack of detailed longitudinal research on the residential mobility of children and young people. To fully understand the impact that residential mobility has on young people, a longitudinal study is needed to track moves over an extended time-period. Cross sectional analysis or a series of point in time measures taken at random intervals, would not be enough as residential moves are likely to be missed. Van Ham and Manley (2012) argue that more severe negative effects can be expected from living in a deprived neighbourhood your whole life, than exposure to such a neighbourhood for only a short period of time (van Ham and Manley 2012). This again highlights the importance of consistent data collection over time to analyse how where you live and where you move is associated with later life outcomes.

In response to the current gap in the literature, in this paper we focus on spatial mobility and present data from the National Pupil Database (NPD) on neighbourhood moves. The aim of this paper is to develop a better understanding of who is moving over the educational life course, whether pupils are 'upgrading' or 'downgrading' in terms of the quality of their neighbourhoods and what difference this makes in terms of educational outcomes.

\section{Literature Review}

The neighbourhood effects literature states that where you live determines your life chances above and beyond individual characteristics (Wilson 1987; Galster 2002; van Ham and Manley 2012). Where people live and where they move over the life course is 
an important factor in understanding life outcomes. In recent years the focus has shifted from those who are "stuck in place" (Sharkey 2012) to include those who are highly mobile. People move for many different reasons. Rossi (1955) found that people move as part of a broad upward economic shift, to nicer homes and better neighbourhoods. Rossi's seminal study on residential mobility took place while there was marked economic growth and prosperity in the United States. Rising incomes meant families could afford to buy homes in the areas they wanted for the first time. These ideas have been taken forward over the last 60 years and addressed by a number of authors (Bird 1976; Clark and Onaka 1983; Lee et al. 1994).

Traditionally, studies of residential mobility have examined local moves within the same labour market, and thus focus on influences within housing markets (Clark and Huang 2003). Whereas long-distance moves are primarily associated with employment opportunities in distant labour markets; often a migration of professionals and are associated with internal migration studies (Clark and Huang 2003). Clark (1982) set out an extensive literature review outlining the distinctions between internal migration and mobility studies. However, studies have developed with the focus not just on who moves, when they move and how far, but reasons and triggers for moves and the effects these have on the individual or family. For example, Clark and Dieleman (1996) studied the household life cycle, noting that moves were caused by different life events and individual and family needs, as well as economic and political influences. More recently (Cordes et al. 2015; Chetty et al. 2015; Leckie 2009; Jelleyman and Spencer 2008) residential mobility has been linked to a range of different socio-economic, educational and health based outcomes, with the focus being not on why people move but how moving can have a positive or negative impact on life chances over and above individual characteristics. This paper therefore uses the term residential mobility to indicate any move made by a pupil within England, as the focus of this paper is not on the distance travelled but the association such a move has on educational outcomes.

Certain life events can trigger home moves such as childbirth (Kulu 2005); union formation and union dissolution (Feijten and van Ham 2010). Gasper et al. (2010) state that moving home is a status attainment strategy on the part of parents to enhance their life chances and those of their children, which builds on Rossi's seminal findings. Lower-income families however, may move due to unstable housing arrangements. These moves may have negative consequences (Coulton et al. 2012; South et al. 2005). Lower-income households may make frequent moves because of economic or social issues. Many moves undertaken by low-income families can be involuntary, especially in the case of forced displacement, when a family for example, are evicted by a private landlord (Coulter et al. 2012). Being mobile therefore should not be assumed to be deliberate, planned or positive. Rather, some families may experience moving as a negative outcome that can be very distressing for an individual or family who do not want to leave their home or neighbourhood (Coulton et al. 2012; Desmond 2015).

Moving frequently, even over short distances can be extremely disruptive for children as they are more reliant on closer geographical peer networks than adults and therefore may be more susceptible to the consequences of a social change or residential move (Sharkey 2012; Cordes et al. 2015; Morris et al. 2016). Bushin (2009) argues that children are often directly involved in the migration decision making process by helping to determine whether a family moves and where they move to. However when moves take place due to economic or social problems children can be 
conceptualised as 'passengers' in relation to the moving process as they rarely explicitly drive such a residential move (Pribesh and Downey 1999). The State of the Nation report (Social Mobility and Child Poverty Commission 2016) ${ }^{1}$ states that both residential and educational stability are very important for children. Because of this they are advising government that social housing tenancies need to be implemented so that the same accommodation is available until the youngest child leaves home.

Residential mobility can be disruptive for all children but often more detrimental for low income groups, especially when moving home comes about as a result of a negative consequence, through socio-economic hardship (Coulton et al. 2012). For certain social classes and specifically for ethnic minorities there are more barriers present to inhibit effective residential mobility than for other social groups. In particular, racial segregation and racial inequities may undermine the probability that ethnic minorities can move to better housing and neighbourhoods. Coulton et al. (2012) highlight that after life-cycle factors, neighbourhood and housing satisfaction were held constant, African-American households in the United States had a lower probability of moving than White households. This pattern suggests that many African-American households may remain in unsatisfactory housing or neighbourhoods due to social and economic barriers to mobility. In the UK a similar pattern exists. Phillips (1988) found that minority ethnic groups tended to be allocated poorer quality housing on worse estates than the White British population in London. The reasons for this were complex, sometimes involving direct discrimination or a decision to concentrate minorities in specific areas and parts of the housing stock (Butler and Hamnett 2011).

Very few studies disentangle the effects of origin neighbourhood from current neighbourhood and personal characteristics, such as ethnicity and socio-economic status (Duncan et al. 1994; Holzer et al. 2008; Cordes et al. 2015). Studies of residential mobility often only look at specific time points and miss out some of the important in-between years. A child for example, may have moved several times over their educational life course but this would not be picked up without extensive longitudinal analysis. Understanding spatial mobility is integral to better understanding life outcomes over and above point in time analysis and social measures such as income or class.

Chetty et al. (2015) study more than five million families that have moved across areas and use quasi-experimental methods to show that neighbourhoods have causal exposure effects on children's outcomes. ${ }^{2}$ They find that every year spent in a better area during childhood increases college attendance rates and earnings in adulthood, so the gains from moving to a better area are larger for children who are younger at the time of the move. Cordes et al. (2015) have studied all students enrolled as first graders in public schools in New York City between 1996/7 and 2007/8. The study found that there is little evidence that moving to higher quality neighbourhoods is related to improved performance; rather, there is consistent evidence that moving neighbourhoods is associated with decreases in both long and short-term student attainment and performance, especially among students who move to lower quality neighbourhoods. However, both studies utilise spatially coarse aggregated data, using U.S States as their geographic scale, which means some of the finer spatial

\footnotetext{
${ }^{1}$ The Social Mobility Commission, are an advisory non-departmental public body, sponsored by the Cabinet Office and the Department for Education.

${ }^{2}$ It is worth noting that neighbourhood in this work was taken to mean a very large region unit far greater in spatial extent than is utilised in the much of the other literature included here.
} 
differences and individual behaviours when reporting on outcomes are missed. The studies also seem to contradict each other somewhat as Chetty et al. (2015) argue that neighbourhoods have an effect on outcomes whereas Cordes et al. (2015) find little evidence that living in a less deprived neighbourhood has any impact on educational outcomes.

Identifying who is moving and how often they are moving is important in understanding and predicting future life outcomes. It seems apparent that more severe negative associations can be expected from living in a deprived neighbourhood your whole life, than exposure to such a neighbourhood for only a short period of time (van Ham and Manley 2012). It is therefore not only important to study who is moving, but also where they are moving to. Some children, for example, may live in an affluent neighbourhood for much of their childhood and only move to a deprived neighbourhood during their final years of school. Thus, their level of exposure to a deprived neighbourhood would be very different to a child that moves between deprived neighbourhoods only, and the effects of those moves on their educational outcomes could also differ as a consequence.

\section{Data}

For this study we use data from the National Pupil Database (NPD). Publicly funded schools and colleges in England have a statutory duty to provide data to the Department of Education since 2002 (Singleton 2010). These are stored as the NPD in a number of data sets. In this paper we track a single cohort of pupils each year who all started school in 2002 and finish compulsory schooling aged 16 in 2013, this is comprised of 583,787 (extracted from the complete NPD) records.

Every student record contains demographic and academic information, including ethnicity, gender, language, Free School Meal (FSM) status (eligibility for a free lunch), school attended and Key Stage 4 (KS4) results. Key stage 4 exams are more commonly known as the General Certificate of Secondary Education (GCSE) or other national equivalent qualifications. Normally a student will study for on average 8 GCSEs in core subjects such as Maths, English and Science as well as additional language and humanities subjects (Gill and Williamson 2016). In the UK, achieving $5 \mathrm{~A}^{*}-\mathrm{C}$ grades has been a benchmark target set for certain employment opportunities or to gain a place in higher education. The grading system for GCSEs has recently changed. Those with lower educational attainment are more likely to experience reduced employment opportunities and earning potential (Marmot, 2010), while successful completion of compulsory education is strongly associated with increased aspirations and life satisfaction (Skalamera and Hummer 2016).

Each GCSE grade is assigned a number of points. The highest possible score is 464 which is equivalent to eight $\mathrm{A}$ *s which are 58 points each. The GCSE capped point score will be used for analysis in this paper as this includes the 8 best GCSE scores. ${ }^{3}$ Although the grading system has changed, this was how GSCE's were scored during the educational life course of the cohort.

To represent the local residential environment within which mobility takes place the NPD data are geocoded and include the Lower Super Output Area (LSOA) codes of the pupil's home for each school year. LSOAs have on average, 1500 residents (Flouri

\footnotetext{
${ }^{3}$ The analysis was also carried out using $5 \mathrm{~A}^{*}$-C as the dependent variable in the three regression models and the outcomes were showing the same pattern in all models.
} 
et al. 2012). LSOA is the lowest scale at which georeferenced data could be obtained for this study. In order to be able to measure neighbourhood quality, the Index of Multiple Deprivation (IMD) is used. The IMD is the government's preferred indicator of deprivation in England (Norman 2010). In order to be able to compare the quality of neighbourhoods across the educational life course, one static score is needed to be applied to all LSOAs. The 2007 IMD score fits roughly in the middle of the educational life cycle running from 2002 to 2013, therefore this score was applied across all years. Neighbourhood characteristics may of course change somewhat over an 11-year period, but in order to compare across the educational life course one static score is needed. In practice, IMD scores do not change dramatically over a decade so using one score across the time period will not impact too greatly on results.

Of the starting cohort of 583,796 pupils, 67,894 (11.6\%) had missing records due to either leaving the country or moving to a school before the end of/or during the educational life cycle, such as moving to an independent school that do not have to report to NPD. As this is a longitudinal study those with missing records were removed from the cohort data set. A further 40,336 (6.9\%) did not have a linked education record for KS4 and very few had a score of zero at KS4, these individuals were removed from analysis. These pupils may have been absent due to illness and a score of zero would therefore skew results.

To analyse whether a residential move had taken place between two consecutive school years, the LSOA codes between two years were compared and where a change was found a move was recorded. If it was the same as the year before a score of 0 was given, if the LSOA code had changed, this indicated a move had taken place and therefore was given a score of 1 . The scores could then be combined to give an overall number of moves made by each pupil within the cohort across the compulsory educational life course. Table 1 reports the cumulative moves and shows that $54 \%$ of the cohort never move home during the educational life course, $46 \%$ move home at least once and with approximately $9 \%$ of the cohort moving more than three times. Five pupils within the cohort move home every school year. ${ }^{4}$

School moves are not focused on in detail in this paper but they are included in the three regression models. School moves were coded in a similar way to LSOA moves, the two school codes in consecutive years were analysed, if it was the same as the year before a score of 0 was given, if the school code had changed, this indicated a move had taken place and therefore was given a score of 1 . Any compulsory school moves, i.e. the transition from junior to secondary school at age 11 was not coded as a move as the majority of children change schools at this point.

\section{Methods}

To examine the association between home moves and changing neighbourhood type on educational attainment, we use multivariable linear regression models. The dependent variable in all three models is Key Stage 4 (KS4) point scores. The models outlined in

\footnotetext{
${ }^{4}$ We acknowledge that by using LSOA code changes to identify moves we will not identify very local moves that occur within an LSOA. However, as we are interested in moves that change the context in which an individual lives and which are potentially more disruptive in terms of social networks omitting these moves is not problematic.
} 
Table 1 NPD cohort: Total number of moves (2002-2013)

\begin{tabular}{llll}
\hline Moves & Number & Freq & Cum. Freq \\
\hline 10 & 5 & 0.001 & 0.001 \\
9 & 27 & 0.005 & 0.006 \\
8 & 156 & 0.03 & 0.036 \\
7 & 483 & 0.1 & 0.136 \\
6 & 1504 & 0.32 & 0.456 \\
5 & 4128 & 0.87 & 1.326 \\
4 & 10,199 & 2.14 & 3.466 \\
3 & 24,354 & 5.12 & 8.586 \\
2 & 54,034 & 11.36 & 19.95 \\
1 & 124,050 & 26.08 & 46.03 \\
0 & 256,626 & 53.96 & 100 \\
& 475,566 & 100 & \\
\hline
\end{tabular}

this paper highlight the association between residential moves and neighbourhood type with educational attainment.

To determine the relationship between LSOA moves and educational attainment, the following model is estimated:

$$
\mathrm{KS} 4=\beta_{\mathrm{o}}+\beta_{1} \mathrm{MOVE}
$$

MOVE is an indicator of whether the student moved LSOA between two consecutive school years across the educational life course. Model 2 determines the relationship between educational attainment (KS4) and LSOA moves (MOVE) controlling for school moves (SCHOOL), ethnicity (ETHNIC) and FSM eligibility (FSM):

$$
\mathrm{KS} 4=\beta_{\mathrm{o}}+\beta_{1} \mathrm{MOVE}+\beta_{2} \mathrm{SCHOOL}+\beta_{3} \mathrm{ETHNIC}+\beta_{4} \mathrm{FSM}
$$

The final model determines the relationship between educational attainment (KS4) and moving between types of neighbourhood (NTYPE) (if the neighbourhood is low, mid or high in level of neighbourhood deprivation) controlling for school moves (SCHOOL), ethnicity (ETHNIC) and FSM eligibility (FSM):

$$
\mathrm{KS} 4=\beta_{\mathrm{o}}+\beta_{1} \mathrm{NTYPE}+\beta_{2} \mathrm{SCHOOL}+\beta_{3} \mathrm{ETHNIC}+\beta_{4} \mathrm{FSM}
$$

\section{Results}

\section{Who is Moving?}

Before analysing regression estimates, we first examine the descriptive statistics for LSOA moves. Table 2 reports the number of home moves made over the educational life course 
Table 2 Home moves by ethnic group 2002-2013 (ranked by no. moves)

\begin{tabular}{|c|c|c|c|c|c|c|c|c|}
\hline \multirow[b]{2}{*}{ Ethnic Group } & \multicolumn{6}{|c|}{ Number of LSOA Moves (\%) } & \multirow[b]{2}{*}{ Total $(\%)$} & \multirow[b]{2}{*}{ Total count } \\
\hline & 0 & 1 & 2 & 3 & 4 & $5+$ & & \\
\hline Black African & 36.9 & 34.9 & 15.2 & 8.2 & 3.2 & 1.6 & 100 & 7795 \\
\hline Asian Other & 41.6 & 31.7 & 16.2 & 6.8 & 2.5 & 1.2 & 100 & 3155 \\
\hline Black Other & 43.0 & 30.5 & 14.8 & 6.8 & 3.0 & 1.9 & 100 & 1850 \\
\hline Mixed White \& Black African & 43.6 & 30.5 & 14.3 & 7.1 & 2.8 & 1.7 & 100 & 1673 \\
\hline Gypsy/Traveller & 44.2 & 23.5 & 14.4 & 9.1 & 4.5 & 4.2 & 100 & 353 \\
\hline Black Caribbean & 46.8 & 29.2 & 12.4 & 6.6 & 2.9 & 2.1 & 100 & 6461 \\
\hline Mixed White \& Black Caribbean & 47.0 & 27.9 & 13.1 & 6.7 & 3.5 & 1.9 & 100 & 6335 \\
\hline White Other & 47.1 & 29.3 & 13.3 & 6.3 & 2.8 & 1.3 & 100 & 8483 \\
\hline Other & 47.7 & 28.2 & 13.7 & 6.9 & 2.4 & 1.0 & 100 & 6862 \\
\hline Mixed Other & 49.3 & 28.3 & 12.7 & 5.8 & 2.5 & 1.4 & 100 & 5234 \\
\hline Bangladeshi & 49.6 & 34.5 & 10.8 & 3.6 & 1.2 & 0.3 & 100 & 5874 \\
\hline Mixed White \& Asian & 52.5 & 26.6 & 12.1 & 5.0 & 2.2 & 1.6 & 100 & 3464 \\
\hline Chinese & 54.6 & 27.9 & 11.4 & 4.2 & 1.1 & 0.7 & 100 & 1276 \\
\hline Pakistani & 54.9 & 28.4 & 10.5 & 4.2 & 1.4 & 0.7 & 100 & 13,324 \\
\hline White British & 55.0 & 25.3 & 11.2 & 5.0 & 2.1 & 1.4 & 100 & 391,787 \\
\hline White Irish & 56.6 & 27.2 & 9.4 & 4.4 & 1.7 & 0.7 & 100 & 1523 \\
\hline Indian & 57.8 & 28.1 & 9.6 & 3.2 & 1.1 & 0.3 & 100 & 10,117 \\
\hline
\end{tabular}

by ethnic group. As a small proportion of movers make more than 5 moves anyone who moves 6 or more times has been grouped into a $5+$ moves category. Turning to the detail in the table Black African pupils move the most, with approximately $65 \%$ moving at least once during the educational life course. Traveller and Romany Gypsy pupils have the highest proportion of pupils (5.3\%) moving five or more times. Almost $60 \%$ of the Indian pupils within the cohort never move during the educational life cycle. This is closely followed by White Irish, White British and Pakistani pupils.

Table 3 shows that a higher proportion of total moves take place for all ethnic groups at the beginning of the educational life course. There is variation among the groups with almost $18 \%$ of Black African pupils and 19\% of Gypsy/Traveller pupils moving during their first year of school, compared with only $8.7 \%$ of Indian pupils. The second column in Table 3 reports the moves made between the penultimate and last year of primary school. This is often a time that strategic moves are made in order to be within a preferred catchment area for secondary schools (Allen et al. 2010). Just under $11 \%$ of Black African and Black Caribbean pupils move and approximately $11 \%$ of Mixed White \& Black African, Mixed White \& Black Caribbean and White Other pupils move at this stage. The final column is home moves made between year 9 and year 10 , just before the start of GCSEs, when the percentage of moves decreases considerably for all groups. Only 7\% of Black African pupils move before the start of GCSE study compared with only $3.3 \%$ of Indian pupils. For all groups, the number of moves decrease the further into the educational life cycle a pupil gets.

Table 4 shows the number of LSOA moves against the number of years a pupil has been eligible for free school meals (FSM) across the educational life course. We expect that there 


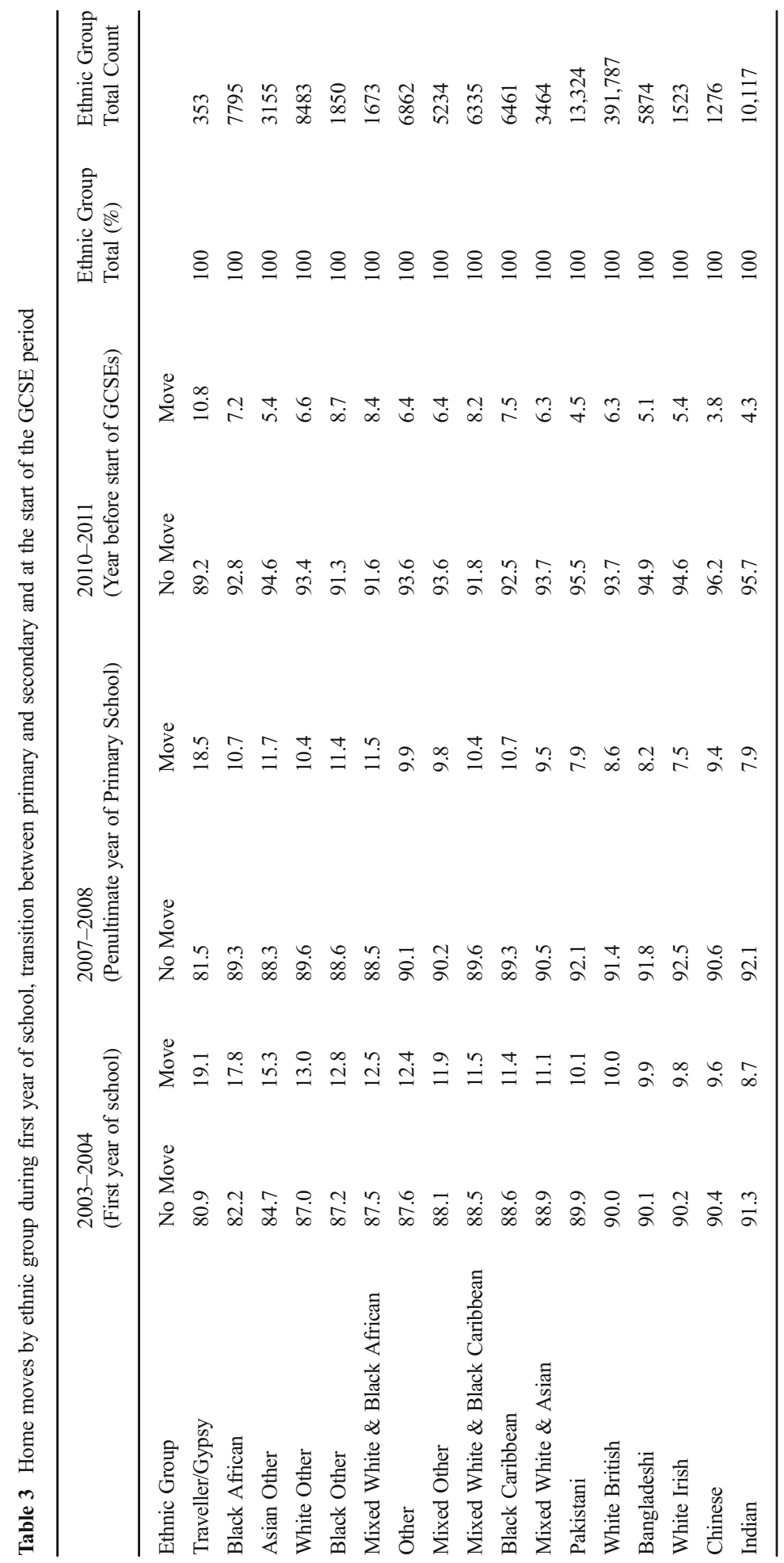


Table 4 LSOA moves by FSM eligibility over the educational life course

\begin{tabular}{|c|c|c|c|c|c|c|c|}
\hline \multirow[b]{2}{*}{ No. of years eligible for FSM } & \multicolumn{6}{|c|}{ No. of LSOA moves (\%) } & \multirow[b]{2}{*}{ Total count } \\
\hline & 0 & 1 & 2 & 3 & 4 & $5+$ & \\
\hline 0 & 60.1 & 25.7 & 9.3 & 3.4 & 1.2 & 0.5 & 332,165 \\
\hline 1 & 41.6 & 28.3 & 15.9 & 8.6 & 3.9 & 2.4 & 20,503 \\
\hline 2 & 39.4 & 28.2 & 16.8 & 9.3 & 4.3 & 3.1 & 16,601 \\
\hline 3 & 38.9 & 28.0 & 16.7 & 9.6 & 4.5 & 3.2 & 14,147 \\
\hline 4 & 38.0 & 27.6 & 17.2 & 10.0 & 4.9 & 3.5 & 12,073 \\
\hline 5 & 37.9 & 27.6 & 17.0 & 10.1 & 5.5 & 3.2 & 11,142 \\
\hline 6 & 38.5 & 26.9 & 17.4 & 9.9 & 4.7 & 3.8 & 10,262 \\
\hline 7 & 39.0 & 26.2 & 17.5 & 9.7 & 5.1 & 4.0 & 9153 \\
\hline 8 & 38.7 & 26.5 & 17.5 & 9.7 & 5.1 & 4.2 & 8970 \\
\hline 9 & 38.3 & 27.8 & 16.5 & 10.1 & 5.2 & 3.7 & 9426 \\
\hline 10 & 40.0 & 26.8 & 16.8 & 9.6 & 4.5 & 3.6 & 11,063 \\
\hline 11 & 48.0 & 26.7 & 14.2 & 6.9 & 2.9 & 1.9 & 19,737 \\
\hline
\end{tabular}

may be an association between home moves and those from lower socio-economic backgrounds. Table 4 shows that $60 \%$ of those who have never been eligible for FSM, have never moved. The proportion of those who have never been eligible for FSM decreases with every additional home move. Of the pupils who have moved 5 or more times, just over $45 \%$ had been eligible for FSM for 6 or more school years, compared with only $11 \%$ of those receiving FSM for 6 or more years but had never moved LSOA. Halse and Ledger (2007) argue that approximately $20 \%$ of children entitled for free school meals may not register as eligible, so it could be that the numbers are somewhat underrepresented and more children who move often are in fact eligible for FSM.

\section{Moving: For Better or Worse?}

Residential mobility is a complex process in which households attempt to reposition themselves in the residential hierarchy. With this in mind it is important to consider if those individuals moving are upgrading or downgrading from their previous neighbourhood. The IMD/scores were grouped into deciles for each of the school years so could be easily comparable across the educational life cycle, 10 being most deprived and 1 being least deprived. Table 5 is a matrix showing the IMD decile group score change between 2002 (the first year of schooling), and 2008 (the final year of primary school). Of the pupils starting in the least deprived neighbourhood, $44 \%$ still lived in the least deprived class of neighbourhood in 2008 despite having moved. Over $67 \%$ of pupils living in one of the most deprived neighbourhoods moved to an equally ranked deprived neighbourhood. This pattern follows through each decile with the majority moving to a similar ranked neighbourhood. A small proportion do upgrade or downgrade neighbourhoods considerably. Between 2002 and 2008, 51 pupils within the cohort moved from one of the least deprived neighbourhoods to one of the most 
Table 5 IMD group change (\%) between the first year of schooling (2002) and the last year of primary school (2008)

\begin{tabular}{|c|c|c|c|c|c|c|c|c|c|c|}
\hline IMD Group & \multicolumn{9}{|c|}{ (2008) } \\
\hline & Low & & & & & & & & & High \\
$(2002)$ & 1 & 2 & 3 & 4 & 5 & 6 & 7 & 8 & 9 & 10 \\
\hline 1 & 44.8 & 11.3 & 8.0 & 6.0 & 4.0 & 3.0 & 1.8 & 0.8 & 0.5 & 0.2 \\
\hline 2 & 13.6 & 35.0 & 9.3 & 7.5 & 5.6 & 4.1 & 2.8 & 1.7 & 1.0 & 0.5 \\
\hline 3 & 10.2 & 10.4 & 34.4 & 8.4 & 6.9 & 5.4 & 3.9 & 2.7 & 1.5 & 0.7 \\
\hline 4 & 7.3 & 8.8 & 8.9 & 33.8 & 7.5 & 6.4 & 4.6 & 3.4 & 1.9 & 1.0 \\
\hline 5 & 6.7 & 8.1 & 8.4 & 8.8 & 34.7 & 7.8 & 6.0 & 4.8 & 2.9 & 1.7 \\
\hline 6 & 5.6 & 7.7 & 8.0 & 8.8 & 9.2 & 35.9 & 8.5 & 6.7 & 4.5 & 2.7 \\
\hline 7 & 4.8 & 6.3 & 7.4 & 8.2 & 9.3 & 10.1 & 38.9 & 9.0 & 6.8 & 4.4 \\
\hline 8 & 3.5 & 5.7 & 6.8 & 7.8 & 9.0 & 9.9 & 11.9 & 43.3 & 11.2 & 7.4 \\
\hline 9 & 2.2 & 4.3 & 5.2 & 6.3 & 8.0 & 9.3 & 11.5 & 14.5 & 51.0 & 14.1 \\
\hline 10 & 1.3 & 2.4 & 3.7 & 4.4 & 6.0 & 8.0 & 10.2 & 13.1 & 18.6 & 67.4 \\
\hline
\end{tabular}

deprived. 242 pupils moved from one of the most deprived neighbourhoods to one of the least deprived neighbourhoods between the start and end of primary school.

Table 6 is a matrix showing the IMD decile group score change between the start of, and 2013, the last year of compulsory schooling. Just over $30 \%$ of pupils living in one of the least deprived neighbourhoods in 2002 at the start of school were living in the same type of neighbourhood at the end of school in 2013 having moved one or more times. Just over $50 \%$ of those who lived in the most deprived neighbourhood in 2002 at the start of school, finished school living in an equally deprived type of neighbourhood, even after moving one or more times. This suggests that those who live in the most deprived neighbourhoods are less likely to upgrade to a better neighbourhood and are more likely to remain in a deprived neighbourhood even after moving. Table 6 shows that $94 \%$ of those who lived in one of the most deprived neighbourhoods ended up living in a neighbourhood within deciles 6 to 10 .

Table 7 decomposes this analysis by ethnicity as well as neighbourhood type in which pupils start and finish school. Neighbourhoods with an IMD score in quintile 1-3 is labelled as low, as these neighbourhoods are the least deprived. Neighbourhoods with an IMD score in quintile $8-10$ is labelled as high, as these neighbourhoods are the most deprived. Neighbourhoods with an IMD score in quintile 4-7 are labelled as mid as these neighbourhoods have neither high nor low levels of deprivation. Almost $35 \%$ of Black African pupils in the cohort move within the most deprived neighbourhoods during the educational life course. In total almost $70 \%$ of Black African pupils either move between or remain in one of the most deprived neighbourhoods. Just under $2 \%$ live in or move between one of the least deprived neighbourhoods. This is also the same for Bangladeshi pupils, with over $40 \%$ living in the same deprived neighbourhood 
Table 6 IMD group change (\%) between the first year of schooling (2002) and the last year of compulsory schooling (2013)

\begin{tabular}{|c|c|c|c|c|c|c|c|c|c|c|}
\hline IMD Group & \multicolumn{9}{|c|}{ (2013) } \\
\hline \multirow{2}{*}{$\begin{array}{c}\text { Low } \\
(2002)\end{array}$} & 1 & 2 & 3 & 4 & 5 & 6 & 7 & 8 & 9 & $\begin{array}{c}\text { High } \\
10\end{array}$ \\
\hline 1 & 30.9 & 14.1 & 10.1 & 7.5 & 5.4 & 3.8 & 2.4 & 1.2 & 0.7 & 0.3 \\
\hline 2 & 17.2 & 18.5 & 11.7 & 9.2 & 7.4 & 5.2 & 3.5 & 2.5 & 1.5 & 0.7 \\
\hline 3 & 12.4 & 12.9 & 17.1 & 10.2 & 8.9 & 6.9 & 5.0 & 3.6 & 2.3 & 1.1 \\
\hline 4 & 9.3 & 11.2 & 11.0 & 15.9 & 9.4 & 8.0 & 6.0 & 4.4 & 2.7 & 1.5 \\
\hline 5 & 8.1 & 10.1 & 10.6 & 11.2 & 16.0 & 9.9 & 7.8 & 6.4 & 3.9 & 2.3 \\
\hline 6 & 6.9 & 9.4 & 9.8 & 11.0 & 11.7 & 16.7 & 11.1 & 9.1 & 6.3 & 3.8 \\
\hline 7 & 6.1 & 8.1 & 9.3 & 10.8 & 11.7 & 13.1 & 19.1 & 11.5 & 9.3 & 6.4 \\
\hline 8 & 4.4 & 6.9 & 8.7 & 9.8 & 11.6 & 13.1 & 15.4 & 22.9 & 15.4 & 10.5 \\
\hline 9 & 3.1 & 5.4 & 6.8 & 8.5 & 10.0 & 12.5 & 15.7 & 20.0 & 31.3 & 20.0 \\
\hline 10 & 1.6 & 3.4 & 4.9 & 6.0 & 7.8 & 10.8 & 14.0 & 18.4 & 26.6 & 53.4 \\
\hline
\end{tabular}

throughout the educational life course and over $30 \%$ moving between the most deprived neighbourhoods. Just over $2 \%$ live in or move between one of the least deprived neighbourhoods. Conversely, just under $10 \%$ of White British pupils move between one of the most deprived neighbourhoods, with $18 \%$ living in the same deprived neighbourhood throughout the educational life course. Over 19\% stay in one of the least deprived neighbourhoods and do not move. Very low proportions of all ethnic groups upgrade or downgrade neighbourhoods considerably, however, 3\% of Mixed White and Black African pupils and almost $3 \%$ of Chinese pupils move from one of the most deprived neighbourhoods to one of the least deprived neighbourhoods. Just over $1 \%$ of Gypsy/Traveller pupils and Mixed White and Black African pupils move from one of the least deprived neighbourhoods to one of the most deprived.

Table 8 lists the neighbourhood type that pupils start and finish school in by FSM eligibility. This shows that over $90 \%$ of those that move between the least deprived neighbourhoods and almost $95 \%$ of those that stay in the same neighbourhood with low levels of deprivation have never been eligible for FSM, compared with $68 \%$ of pupils who move between the most deprived neighbourhoods being eligible at some stage of the educational life course, over half of these pupils that move between deprived neighbourhoods have been eligible for 6 or more years. On the whole those that move within each IMD category are more likely to be eligible for FSM than those that stay in the same place throughout the educational life course.

\section{Does Moving Matter?}

In order to understand if moving has any impact on pupils, educational attainment is being used as the main outcomes variable for this research, using KS4 (GCSE) results as a marker 


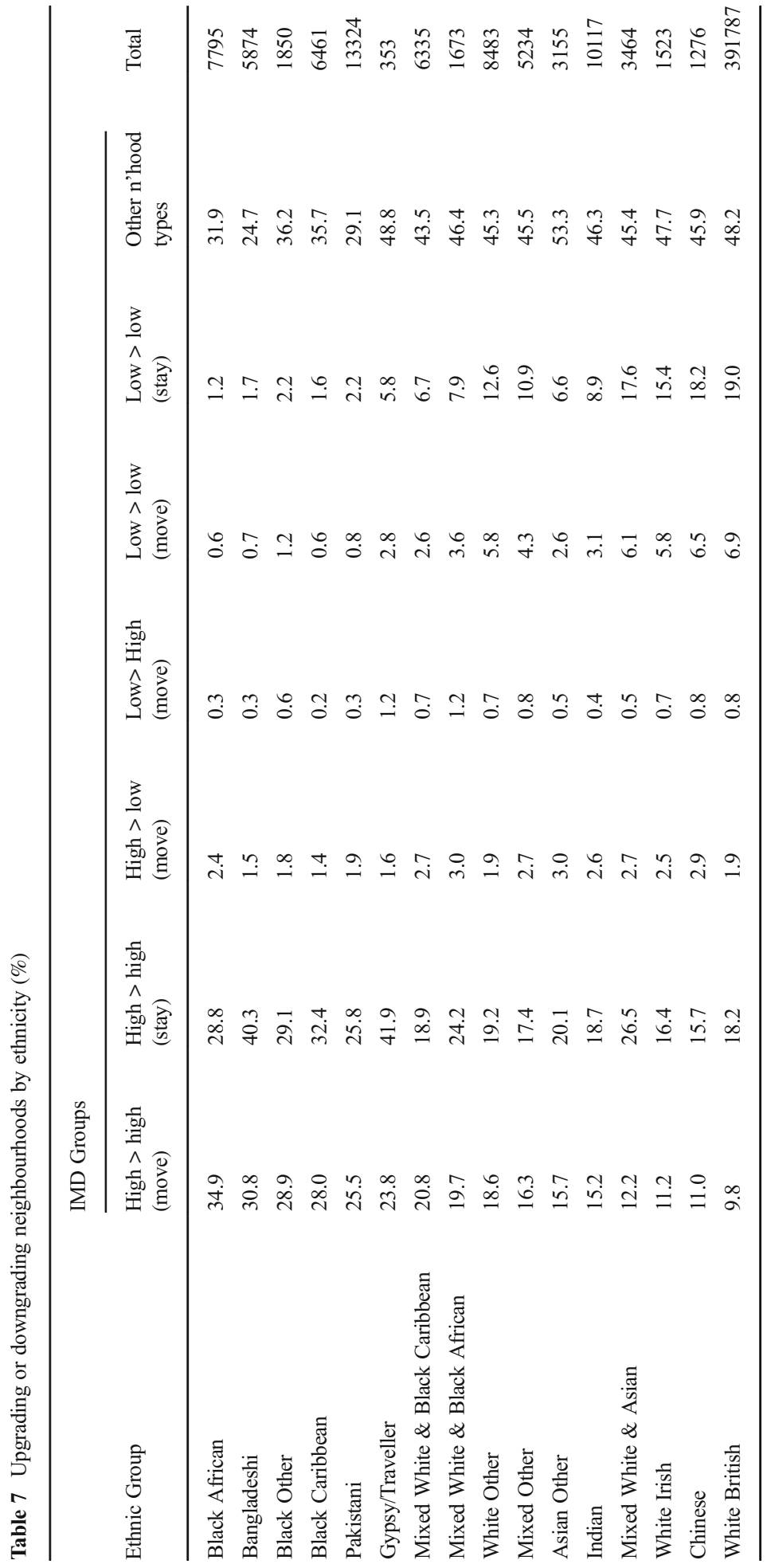


Table 8 Upgrading or downgrading neighbourhoods by FSM eligibility (\%)

\begin{tabular}{|c|c|c|c|c|c|c|}
\hline \multirow[t]{2}{*}{ IMD group } & \multicolumn{2}{|c|}{ Never eligible for } & \multicolumn{2}{|c|}{ Eligible for FSM for } & \multicolumn{2}{|c|}{ Eligible for FSM for } \\
\hline & FSM & $(\%)$ & $1-5$ years & $(\%)$ & $6+$ years & $(\%)$ \\
\hline High $>$ high (move) & 17,041 & 31.9 & 15,016 & 28.1 & 21,356 & 40.0 \\
\hline High > high (stay) & 41,545 & 53.2 & 16,232 & 20.8 & 20,372 & 26.1 \\
\hline High $>$ low & 3352 & 67.0 & 1103 & 22.0 & 549 & 11.0 \\
\hline Low $>$ high & 1046 & 63.2 & 387 & 23.4 & 223 & 13.5 \\
\hline Low > low (move) & 14,659 & 90.6 & 1232 & 7.6 & 288 & 1.8 \\
\hline Low > low (stay) & 51,759 & 94.7 & 2153 & 3.9 & 740 & 1.4 \\
\hline
\end{tabular}

of attainment. Table 9 shows the relationship between home moves and KS4 point score, using zero moves as the baseline. With each additional home move, KS4 point scores decrease, indicating that the more a pupil moves home during the educational life course the lower their KS4 point score will be, all of which are statistically significant. Those that move five or more times will score 87 points less than a pupil who never moves. In terms of GCSEs the average pupil who never moves would score 298 points which is equivalent to achieving five Cs and three Ds. The average pupil who moves 5 or more times would score 210 point which is equivalent to six Es and two Fs.

Table 9 only focuses on home moves in relation to KS4 point score, and only explains $1 \%$ of the variance. It is therefore necessary to control for other factors such as ethnicity and FSM eligibility. The literature also highlights that factoring in school moves is also important, as the disruption of moving to a new school, getting to know a new syllabus, new teachers and peers can be an unsettling time which can impact on educational attainment. Table 10 therefore controls for ethnicity, FSM eligibility and school moves. The model still shows that with each additional home move, KS4 point scores decrease. The effect has lessened but there is still over a 34 point difference between those that move five or more times and those that never move which is equivalent to a grade B at GCSE. Interestingly, when controlling for FSM eligibility and home moves, using White British as the baseline, all ethnic groups, other than Traveller/Gypsy pupils are predicted to have higher overall KS4 point scores. The model therefore suggests that a White British pupil

Table 9 Model 1- linear regression output of home moves and KS4 point scores

\begin{tabular}{|c|c|c|c|c|c|}
\hline KS4 points & Coef. & Std. Err. & $P$ Value & \multicolumn{2}{|c|}{$95 \%$ Conf. Interval } \\
\hline \multicolumn{6}{|c|}{$\begin{array}{l}\text { Home Moves } \\
\text { Reference: } 0 \text { Moves }\end{array}$} \\
\hline 1 & -12.19 & 0.38 & $<0.01$ & -12.95 & -11.45 \\
\hline 2 & -31.79 & 0.52 & $<0.01$ & -32.81 & -30.76 \\
\hline 3 & -48.89 & 0.74 & $<0.01$ & -50.34 & -47.44 \\
\hline 4 & -64.33 & 1.11 & $<0.01$ & -66.52 & -62.14 \\
\hline $5+$ & -87.05 & 1.41 & $<0.01$ & -89.81 & -84.29 \\
\hline cons & 297.49 & 0.22 & $<0.01$ & 297.06 & 297.91 \\
\hline
\end{tabular}


Table 10 Model 2 - linear regression output of home moves and KS4 point scores, controlling for ethnicity, school moves and FSM eligibility

\begin{tabular}{|c|c|c|c|c|c|}
\hline KS4 Points & Coef. & Std. Err. & $P$ value & \multicolumn{2}{|c|}{$95 \%$ Conf. Interval } \\
\hline \multicolumn{6}{|l|}{ LSOA moves } \\
\hline \multicolumn{6}{|l|}{ Reference: 0 Moves } \\
\hline 1 & -4.35 & 0.36 & $<0.01$ & -5.06 & -3.64 \\
\hline 2 & -12.37 & 0.51 & $<0.01$ & -13.36 & -11.38 \\
\hline 3 & -19.02 & 0.72 & $<0.01$ & -20.43 & -17.60 \\
\hline 4 & -25.07 & 1.08 & $<0.01$ & -27.19 & -22.95 \\
\hline 5 & -34.28 & 1.38 & $<0.01$ & -37.00 & -31.57 \\
\hline \multicolumn{6}{|l|}{ Ethnic Group } \\
\hline \multicolumn{6}{|c|}{ Reference: White British } \\
\hline Bangladeshi & 51.90 & 1.37 & $<0.01$ & 49.22 & 54.58 \\
\hline Indian & 50.03 & 1.04 & $<0.01$ & 47.98 & 52.07 \\
\hline Pakistani & 9.77 & 0.92 & $<0.01$ & 7.98 & 11.57 \\
\hline Black & 33.84 & 0.84 & $<0.01$ & 32.18 & 35.49 \\
\hline Chinese & 88.69 & 2.90 & $<0.01$ & 83.00 & 94.38 \\
\hline Mixed & 24.67 & 0.82 & $<0.01$ & 23.06 & 26.28 \\
\hline Other & 52.95 & 1.05 & $<0.01$ & 50.89 & 55.01 \\
\hline White Other & 43.99 & 1.05 & $<0.01$ & 41.93 & 46.05 \\
\hline Traveller/Gypsy & -69.32 & 5.51 & $<0.01$ & -80.12 & -58.52 \\
\hline School Moves & -5.93 & 0.20 & $<0.01$ & -6.32 & -5.54 \\
\hline FSM & -81.77 & 0.34 & $<0.01$ & -82.45 & -81.10 \\
\hline cons & 313.42 & 0.24 & $<0.01$ & 312.95 & 313.89 \\
\hline
\end{tabular}

eligible for FSM, who has moved home would have a lower KS4 point score than an ethnic minority pupil in the same situation.

The model takes into account school moves, but more analysis is needed to ascertain the impact of each additional school move and whether certain ethnic and social groups are more affected by home or school moves, and how educational attainment is impacted by those that move both home and school. The model also shows that those that have received or have ever been eligible for FSM on average achieve 81 points less than those who do not receive FSM. This is the difference between getting eight Cs and eight Ds at GCSE, which could have a large impact on future career or educational opportunities.

In order to analyse whether moving to a better or worse neighbourhood has any impact on educational attainment, the cohort were grouped into twelve categories, these were created by comparing the type of neighbourhood a pupil was living in at the start of school in 2002, with the type of neighbourhood they were living in during their final compulsory year of schooling in 2013. Group 1 are pupils who have not moved and have lived in one of the least deprived neighbourhood throughout the educational life cycle, group 2 are pupils who have moved from one of the least deprived neighbourhoods to a similar type of neighbourhood, group 3 are those that have moved from one of the least deprived neighbourhood to a middle group neighbourhood, group 4 are those that moved from a middle group neighbourhood to one of the least deprived 
neighbourhoods. Group 5 are those that have not moved and lived in a middle group neighbourhood throughout the educational life course. Group 6 are those that have moved from a middle group neighbourhood to a similar type of neighbourhood. Group 7 are those that have moved from one of the most deprived to one of the least deprived neighbourhoods. Group 8 are those that have moved from one of the least deprived to the most deprived neighbourhoods. Group 9 are those that have moved from one of the most deprived neighbourhood to a middle grouped neighbourhood. Group 10 are those that move from a middle group neighbourhood to one of the most deprived neighbourhoods. Group 11 are those that have not moved but lived in one of the most deprived neighbourhoods throughout the educational life course and group 12 are those that have moved from one of the most deprived neighbourhoods to a similar type of neighbourhood. The groups were inputted into a regression model along with KS4 results, FSM eligibility and ethnicity, with group 1 (those that remain in one of the least

Table 11 Model 3- linear regression output analysing the relationship between IMD group and KS4 results, controlling for FSM eligibility and ethnicity

\begin{tabular}{|c|c|c|c|c|c|}
\hline & Coef. & Std. Err. & $P$-value & \multicolumn{2}{|c|}{ 95\% Conf. Interval } \\
\hline \multicolumn{6}{|l|}{$\begin{array}{l}\text { IMD group change } \\
\text { Reference: Low>Low (stay) (Group 1) }\end{array}$} \\
\hline Low > Low (move) (Group 2) & -3.74 & 0.69 & 0.01 & -5.10 & -2.39 \\
\hline Low > Mid (move) (Group 3) & -22.54 & 0.88 & 0.01 & -24.27 & -20.81 \\
\hline Mid > Low (move) (Group 4) & -22.33 & 0.77 & 0.01 & -24.27 & -20.81 \\
\hline Mid > Mid (stay) (Group 5) & -32.68 & 0.48 & 0.01 & -33.62 & -31.74 \\
\hline Mid > Mid (move) (Group 6) & -43.37 & 0.63 & 0.01 & -44.60 & -42.14 \\
\hline High > Low (move) (Group 7) & -43.66 & 1.13 & 0.01 & -45.87 & -41.46 \\
\hline Low > High (move) (Group 8) & -51.72 & 1.79 & 0.01 & -55.22 & -48.22 \\
\hline High > Mid (move) (Group 9) & -60.55 & 0.72 & 0.01 & -61.96 & -59.14 \\
\hline Mid > High (move) (Group 10) & -66.68 & 0.89 & 0.01 & -68.42 & -64.94 \\
\hline High > High (stay) (Group 11) & -70.90 & 0.53 & 0.01 & -71.95 & -69.85 \\
\hline High $>$ high (move) (Group 12) & -80.35 & 0.62 & 0.01 & -81.57 & -79.14 \\
\hline \multicolumn{6}{|l|}{$\begin{array}{l}\text { Ethnicity } \\
\text { Reference: White British }\end{array}$} \\
\hline Bangladeshi & 73.35 & 1.34 & 0.01 & 70.73 & 75.98 \\
\hline Indian & 62.95 & 1.02 & 0.01 & 60.95 & 64.94 \\
\hline Pakistani & 30.97 & 0.90 & 0.01 & 29.20 & 32.74 \\
\hline Black & 53.25 & 0.83 & 0.01 & 51.52 & 54.77 \\
\hline Chinese & 91.96 & 2.83 & 0.01 & 86.42 & 97.40 \\
\hline Mixed & 31.39 & 0.80 & 0.01 & 29.82 & 32.96 \\
\hline Other & 60.69 & 1.02 & 0.01 & 58.69 & 62.70 \\
\hline White Other & 48.89 & 1.02 & 0.01 & 46.88 & 50.89 \\
\hline Traveller/Gypsy & -71.84 & 5.36 & 0.01 & -82.36 & -61.33 \\
\hline School moves & -5.97 & 0.36 & 0.01 & -6.33 & -5.61 \\
\hline FSM & -62.04 & 0.36 & 0.01 & -62.75 & -61.34 \\
\hline cons & 340.98 & 0.37 & 0.01 & 340.27 & 341.70 \\
\hline
\end{tabular}


deprived neighbourhoods, and never move throughout the educational life course) as the baseline. Table 11 lists the regression output.

Table 11 shows that pupils within the cohort that move between the most deprived neighbourhoods, score on average 80 points lower than the baseline group (those that live in one of the least deprived neighbourhoods and never move). Those that move between deprived neighbourhoods do worse on average at GCSE (scoring 11 points less) than those who stay living within the same deprived neighbourhood throughout school, this is the case for those that live in the least deprived neighbourhood and mid deprived neighbourhoods, where movers appear to always do worse than those pupils who stay in the same place throughout the educational life course. Those that move from a deprived neighbourhood to a less deprived neighbourhood do better than those who only move between deprived neighbourhoods, but still score on average 43 points less than the base line group. Those that move between the least deprived neighbourhoods, although only marginal, still score on average 4 points less than the baseline group which again endorses that moving is more detrimental to educational outcomes than staying in the same place. The regression output also highlights how living in a more deprived neighbourhood throughout the educational life cycle impacts negatively on educational attainment compared to those that live in the least deprived neighbourhoods.

Although this initial analysis highlights some interesting findings, the data at present is grouped so that it is possible to see who has upgraded and downgraded neighbourhood or those that have moved between deprived neighbourhoods and affluent neighbourhoods between the first and last year of compulsory schooling. However, a limitation with this method, is that it is not possible to analyse individual sequences, those that may have started school in an affluent neighbourhood and finished school in an affluent neighbourhood, may have spent several years in a deprived neighbourhood, yet this is not being picked up by the current groupings.

\section{Discussion and Conclusions}

This paper has demonstrated a method of understanding processes of residential mobility across the educational life course. The analyses presented show that very small proportions of pupils upgrade or downgrade their neighbourhood throughout their schooling and are much more likely to move between similar types of neighbourhood, reinforcing the idea of being "stuck in place" for those in the most deprived neighbourhoods (Sharkey 2012). The multivariable linear regression models show that there is a relationship between residential moves, individual characteristics and educational attainment at age 16. With every additional home move KS4 points score decrease highlighting that, on average, the more a young person moves the greater impact this will have on educational attainment. The data shows that residential mobility is more negatively associated with the educational outcomes of those living in the most deprived neighbourhoods. It seems apparent that more severe negative associations can be expected from living in a deprived neighbourhood your whole life, than exposure to such a neighbourhood for only a short period of time (van Ham and Manley 2012). The results showed that those that move between deprived neighbourhoods do worse on average compared to all other pupils, even those that stay in the same deprived neighbourhood throughout the educational life course. 
The analyses show that certain ethnic groups have more of a propensity to move than others, with over two thirds of Black African pupils moving one or more times over the educational life course compared with only $40 \%$ of Indian pupils. One of the main possible reasons for this could be that Indians have the highest proportion of owner occupied housing, compared with Black African who rely much more heavily on social housing and private rentals (Lancaster and McCarthy 2014). Privately rented housing can be very unstable with short fixed term tenancies that are not guaranteed to be extended (Lancaster and McCarthy 2014). Rents have also risen steeply alongside the increased demand. This may therefore cause families to have to move to cheaper accommodation if they are unable to afford rent increases.

There is a long-standing line of research that explores how neighbourhoods shape educational attainment, with consistent findings that students living in poor neighbourhoods experience worse outcomes than their peers (Brooks-Gunn et al., 1997; Pribesh and Downey 1999). While this is extremely valid and important in terms of academic research and Government policy, residential mobility between deprived areas, as shown in this paper, has more of an impact than just being 'stuck in place'. This therefore needs to be taken into account when studying the inequalities of educational attainment, as currently there is little focus on how moving, which is especially problematic for families in unstable housing or those in experiencing economic hardship is impacting on education. It is not purely a case of where you live determining your outcomes, but also how often you move home in childhood and adolescence.

The Local Government Association (2017) stated that councils are providing temporary housing for approximately 120,540 children and their families. Temporary housing provides little stability as a family may have to move at any time. Placement in temporary accommodation, is often at a distance from previous support networks and can lead to individuals and families falling through the net and becoming disengaged from health, education, social care and welfare support systems (HM Government, 2010). This paper has highlighted how with each additional move, educational attainment is more negatively impacted. Those who are therefore highly mobile, especially those who are regularly moving between temporary accommodations for example, will be most at risk of poor educational outcomes.

This paper looks in depth at how residential mobility is associated with educational attainment at KS4, further research could also consider Key Stage 1 and Key Stage 2 results to analyse how moving is associated with earlier educational attainment. This paper looks at moves made between ages 5 and 16; across the entire compulsory educational life course, further research could also analyse at which time point across the educational life course moves take place to examine whether there are certain time points that more negatively associate with educational outcomes. This paper focuses specifically on residential moves, all three models however take into account school moves, further research could focus in more detail on school moves to analyse the association with educational attainment. Building on the work of Clark (1982) highlighting the differences between residential mobility and internal migration, an opportunity for further research would be to analyse distance moved and whether educational outcomes change dependent on how far the pupil has moved, as it may be that those that move further distances are more detached from familiar peer networks and environment and are therefore more likely to experience the negative associations 
of moving, there is also an opportunity to adopt other methodological techniques such as sequence analysis.

This paper has built on existing literature (Chetty et al. 2015; Cordes et al. 2015) by using individual level data and tracking residential moves for each consecutive school years across the entire compulsory educational life course. The analysis has highlighted that the notion of "stuck in place" (Sharkey 2012) is still highly relevant, but it is being "stuck in type of place" that has more of an association with educational attainment, those who stay in the same deprived neighbourhood throughout school achieve 80 points less at KS4 than their peers who live in one of the same least deprived neighbourhoods. The data however has clearly shown that those that between certain types of neighbourhoods are expected to do worse at KS4 than their peers who stay within the same type of neighbourhood and never move throughout the educational life course. This is important for policy makers as often the focus is on the neighbourhood, rather than those who are moving between them.

Acknowledgements Amy Sweet is funded by an ESRC PhD studentship in Advanced Quantitative Methods.

\section{Compliance with Ethical Standards}

Conflict of Interest The authors declare that they have no conflict of interest.

Open Access This article is distributed under the terms of the Creative Commons Attribution 4.0 International License (http://creativecommons.org/licenses/by/4.0/), which permits unrestricted use, distribution, and reproduction in any medium, provided you give appropriate credit to the original author(s) and the source, provide a link to the Creative Commons license, and indicate if changes were made.

\section{References}

Allen, R., Burgess, S. and Key, T. (2010) Choosing secondary school by moving house: School quality and the formation of neighbourhoods, CMPO WP 10/238, CMPO.

Bird, H. (1976). Residential mobility and preference patterns in the public sector of the housing market. Institute of British Geographers, Transactions, 1, 20-33.

Brooks-Gunn, J., \& Duncan, G. (1997). The effects of poverty on children and youth. The Future of Children, $7,55-71$.

Bushin, N. (2009). Researching family migration decision-making: A children-in-families approach. Population, Space and Place, 15, 429-443.

Butler, T., \& Hamnett, C. (2011). Ethnicity, class and aspiration: Understanding London's new east end. Policy Press, Bristol.

Chetty, R., Hendren, N., \& Katz, L. (2015). The effects of exposure to better neighbourhoods on children: New evidence from the moving to opportunity experiment. Working Paper.

Clark, W. A. V. (1982). Recent research on migration and mobility: A review and interpretation. Progress in Planning, 18, 1-56.

Clark, W. A. V., \& Onaka, J. (1983). Life cycle and housing adjustment as explanations of residential mobility. Urban Studies, 20, 47-57.

Clark W. A. V., \& Dieleman F. M. (1996). Households and housing: Choice and Outcomes in the Housing Market (Centre for Urban Policy Research, New Brunswick, NJ).

Clark, W.A.V., \& Huang Y.Q. (2003). The life course and residential mobility in British housing markets. Environment and Planning A, 35(2), 323-339. 
Cordes, S. A., Schwartz, A. E., Stiefel, L., \& Zabel, J. (2015). Is neighbourhood destiny? Exploring the link between neighbourhood mobility and student outcomes. Urban Studies, 10, 400-417.

Coulter, R., van Ham, M., \& Feijten, P. (2012). Partner (dis)-agreement on moving desires and the subsequent moving behaviour of couples. Population, Space and Place, 18, 16-30.

Coulton, C. J., Theodos, B., \& Turner, M. A. (2012). Residential mobility and Neighbourhood change: Real Neighbourhoods under the microscope. Cityscape: A Journal of Policy Development and Research, 14, 55-90.

Desmond, M. (2015) Unaffordable America: Poverty, housing, and eviction. Fast Focus, Institute for Research on Poverty 22.

Duncan, G., Brooks-Gunn, J., \& Klebanov, P. (1994). Economic deprivation and early-childhood development. Child Development, 65, 296-318.

Feijten, P., \& Van Ham, M. (2010). The impact of splitting up and divorce on housing careers in the UK. Housing Studies, 25(4), 483-507.

Flouri, E., Mavroveli, S., \& Tzavidis, N. (2012). Cognitive ability, neighbourhood deprivation, and young children's emotional and behavioural problems. Social Psychiatry Epidemiology, 47, 985-992.

Galster, G. (2002). An economic efficiency analysis of deconcentrating poverty populations. Journal of Housing Economics, 11(4), 303-329.

Gasper, J., DeLuca, S., \& Estacion, A. (2010). Coming and going: Explaining the effects of residential and school mobility on adolescent delinquency. Social Science Research, 39(3), 459-476.

Gill, T., Williamson, J. (2016) Uptake of GCSE subjects 2015. Statistics Report Series No. 107. Available at: http:/www.cambridgeassessment.org.uk/Images/307016-uptake-of-gcse-subjects-2015.pdf.

Halse, J. and Ledger, A. (2007) The use of free school meal status as a proxy for socioeconomic status: Evidence from matching the Longitudinal Study of Young People in England to the National Pupil Database. Available at:https://s3.amazonaws.com/sitesusa/wpcontent/uploads/sites/242/2014/05/2007 FCSM_Halse.VI-C.pdf.

Hedman, L., Manley, D., Van Ham, M., \& Östh, J. (2013). Cumulative exposure to disadvantage and the intergenerational transmission of neighbourhood effects. Journal of Economic Geography, 15(1), 195-215.

Holzer, H., Schanzenbach, D., Duncan, G., \& Ludwig, J. (2008). The economic costs of childhood poverty in the United States. Journal of Children and Poverty, 14(1), 41-61.

Jelleyman, T., \& Spencer, N. (2008). Residential mobility in childhood and health outcomes: A systematic review. Journal of Epidemiology and Community Health, 62(7), 584-592.

Kulu, H. (2005). Migration and fertility: competing hypotheses re-examined. European Journal of Population 21, 51-87.

Lancaster, M. and McCarthy, T. (2014) When the golden dust settles - housing in hackney, Newham and tower hamlets after the Olympics. Shelter publication.

Leckie, G. (2009). The complexity of school and neighbourhood effects and movements of pupils on school differences in models of educational achievement. Journal of the Royal Statistical Society: Series A (Statistics in Society), 172(3), 537-554.

Lee, B. A., Oropesa, R. S., \& Kanan, J. W. (1994). Neighbourhood context and residential mobility. Demography, 31, 249-270.

Local Government Association (2017) Housing our homeless households, Local government association publication.

Morris, T., Dorling, D., \& Davey Smith, G. (2016). How well can we predict educational outcomes? Examining the roles of cognitive ability and social position in educational attainment. Contemporary Social Science.

Norman, P. (2010). Identifying change over time in small area socio-economic deprivation. Applied Spatial Analysis and Policy, 3(2-3), 107-138.

Phillips, D. (1988). Race and housing in London's east end: Continuity and change. New Community, 14, 356369.

Pribesh, S., \& Downey, D. B. (1999). Why are residential and school moves associated with poor school performance? Demography, 36, 21-534.

Rossi, P., (1955) Why families move: A study in the social psychology of urban residential mobility, Glencoe: Free Press.

Sharkey, P. (2012). Stuck in place: Urban Neighbourhoods and the end of progress toward racial equality. Chicago: University of Chicago Press.

Sharkey, P., \& Elwert, F. (2011). The legacy of disadvantage: Multigenerational Neighbourhood effects on cognitive ability. American Journal of Sociology, 116(6), 1934-1981.

Singleton, A. D. (2010). The Geodemographics of educational progression and their implications for widening participation in higher education. Environment and Planning A, 42(11), 2560-2580. 
Skalamera, J., \& Hummer, R. A. (2016). Educational attainment and the clustering of health-related behaviour among U.S. young adults. Preventive Medicine, 84, 83-89.

Social Mobility and Child Poverty Commission (2015) State of the nation 2015: Social mobility and child poverty in great Britain, London: The Stationery Office.

Social Mobility and Child Poverty Commission (2016) State of the nation 2016: Social mobility and child poverty in great Britain, London: The Stationery Office.

South, S. J., Crowder, K., \& Chavez, E. (2005). Exiting and entering high-poverty Neighbourhoods: Latinos, blacks, and Anglos compared. Social Forces, 84(2), 873-900.

van Ham, M., \& Manley, D. (2012). Neighbourhood effects research at a crossroads. Ten challenges for future research, Environment and Planning A, 44, 2787-2793.

van Ham, M., Hedman, L., Manley, D., Coulter, R., \& Östh, J. (2014). Intergenerational transmission of neighbourhood poverty: An analysis of neighbourhood histories of individuals. Transactions of the Institute of British Geographers, 39(3), 402-417.

Wilson W J (1987) The truly disadvantaged: The inner city, the underclass and public policy. Chicago: University of Chicago Press. 